\title{
On real and abstracted geometries of boreal forest plants
}

\author{
L. Aro ${ }^{1}$ and A.T.K. Ikonen ${ }^{2}$ \\ ${ }^{1}$ Finnish Forest Research Institute, Kaironiementie 15, 39700 Parkano, Finland \\ ${ }^{2}$ Posiva Oy, Olkiluoto, 27160 Eurajoki, Finland
}

\begin{abstract}
In Finland, Olkiluoto Island on the western coast has been selected as a repository site for spent nuclear fuel disposal. A safety criterion is that typical exposures (dose rates) to flora and fauna should be demonstrated to be lower than those that according to best available knowledge could cause detrimental effect. To increase the confidence of dose assessment to flora, some selected plant species were measured in field conditions. This paper presents the results of the field campaign and discusses on the realism of the common assumption of ellipsoidal geometry applied to the plants in dose assessments of the other biota.
\end{abstract}

\section{INTRODUCTION}

In Finland, Olkiluoto Island on the western coast has been selected as a repository site for spent nuclear fuel disposal. With approaching licensing steps (application for nuclear construction licence in 2012), the biosphere assessment demonstrating the long-term safety of the repository is developed into more and more site specific. One of the safety criteria is to demonstrate that typical exposures (practically dose rates) to flora and fauna remain, with high confidence, smaller than those that could, based on best available scientific expertise, lead to any detrimental effects. Based on earlier test case and assessment results, and on an international BIOPROTA study [1], the expected dose rates to the biota are in most cases small and variations within the size of the assumed geometry contribute little to the overall uncertainty.

However, in the context of providing site-specific input data to the assessment, and on the other hand at the same time aiming at conceptual integrity, defining appropriate dimensions for the ellipsoids representing plants is in most cases difficult as the shape and structure of the plants clearly deviate from an ellipsoid - unlike the case with most animal species. This paper discusses on the geometry issue based on field data from boreal forests at Olkiluoto.

\section{MATERIAL AND METHODS}

\subsection{Plant species}

In this study selection of key plant species was based on earlier vegetation inventories at Olkiluoto [2], frequency of plant species and their importance in food chains. Hence bilberry (Vaccinium myrtillus) was selected to represent deciduous dwarf shrubs, lingonberry (Vaccinium vitis-idaea) evergreen dwarf shrubs, chickweed wintergreen (Trientalis europaea) and wood-sorrel (Oxalis acetosella) lower herbs, wavy hair-grass (Deschampsia flexuosa) grasses, reindeer lichen (Cladina rangiferina) lichens and redstemmed feather-moss (Pleurozium schreberi) mosses on mineral soil sites. All the selected plant species belong to a group of most common plant species in Southern-Finland [3]. Red-stemmed feather-moss also is commonly used as a bioindicator species in environmental studies. Scots pine and Norway spruce dominate forests on Olkiluoto Island [4]. 
Table 1. Basic information on study sites including dominant tree species.

\begin{tabular}{|l|l|c|c|}
\hline Site code & Site type & Tree species & Stem volume $\left(\mathrm{m}^{3} / \mathrm{ha}\right)$ \\
\hline OL-FIP4-OA4 & Herb-rich heath forest & Scots pine & 242 \\
\hline OL-FET923279 & Xeric heath forest & Scots pine & 66 \\
\hline OL-FET925276 & Rocky forest & Scots pine & 32 \\
\hline Lastensuo mire & Sphagnum fuscum bog - tall-sedge fen & Scots pine & $0-88$ \\
\hline
\end{tabular}

For mire vegetation, bog bilberry (Vaccinium uliginosum), heather (Calluna vulgaris) and Labrador tea (Ledum palustre) were selected to represent dwarf shrubs and cloudberry (Rubus chamaemorus) herbs.

Selection criteria for the reference organisms include ecological niche, intrinsic radiosensitivity, radioecological sensitivity, distribution (e.g. presence year-round), suitability to research and monitoring and protected status [5]. It seems that the criteria are quite well in accordance with the key species we have selected for this study. However, intrinsic radiosensitivity of the selected species is an uncertain issue, especially regarding long-lived radionuclides characteristic to releases from deep repositories.

\subsection{Sites}

Three of the study sites located at Olkiluoto (Table 1, see also [6]). FIP4 is an intensively studied forest monitoring plot. FET measurement plots constitute a grid of systematically located plots with the purpose of describing the biomass distribution of forests and monitoring changes in the tree stands [4]. Lastensuo mire (area 440 ha, elevation $44-48 \mathrm{~m}$ a.s.1.) belongs to the sites chosen as analogues to the mires expected to form with post-glacial land uplift in Olkiluoto (see [7], and the paper by Haapanen et al. to this conference) and is located relatively near to Olkiluoto Island, in Eurajoki municipality. The centre of this raised bog is almost treeless, Scots pine being the dominant tree species in forested areas of the mire.

\subsection{Sampling and measurements}

Plants species were measured from plots (radius $9.77 \mathrm{~m}$ ) where two inventory lines were placed from south-west to north-east and from south-east to north-west (Fig. 1). On the FIP4 intensive monitoring plot only one inventory line (length $30 \mathrm{~m}$ ) was used due to different design and monitoring system of the plot. Width in two directions and height of selected plant species were measured with an accuracy of $0.5 \mathrm{~cm}$ systematically along inventory lines. Only living part of mosses was measured. A subset of the plant individuals and blocks of moss and lichen were sampled for dry mass $\left(105^{\circ} \mathrm{C}\right)$ determination in a laboratory. Because of different habitat demands of plants all selected species were not occurring on every site.

\subsection{Dose rate calculations}

Dose rates of ionising radiation from a postulated repository release scenario to the plants were computed using the ERICA Assessment Tool [8] with its default settings except for the plant dimensions and weights reported below. For the concentrations in the environmental media, the results from a case of a 4-mm initial hole in a single spent nuclear fuel canister combined to high groundwater flow rate in the geosphere (Sh4Q-A, [9]) for a suite of typical dominating nuclides in the assessment were utilised: $5.41 \times 10^{-3} \mathrm{~Bq} / \mathrm{kg}_{\mathrm{dw}}$ of I-129, $6.50 \times 10^{-6} \mathrm{~Bq} / \mathrm{kg}_{\mathrm{dw}}$ of Ni-59 and $4.98 \times 10^{-8} \mathrm{~Bq} / \mathrm{kg}_{\mathrm{dw}}$ of Se-79 as the maximum concentrations in forest top soil within the 10000 -year dose assessment time window applied, for each nuclide separately (on occurrence of the maximum total dose rate, some of the nuclides show a lower concentration than their maximum). 


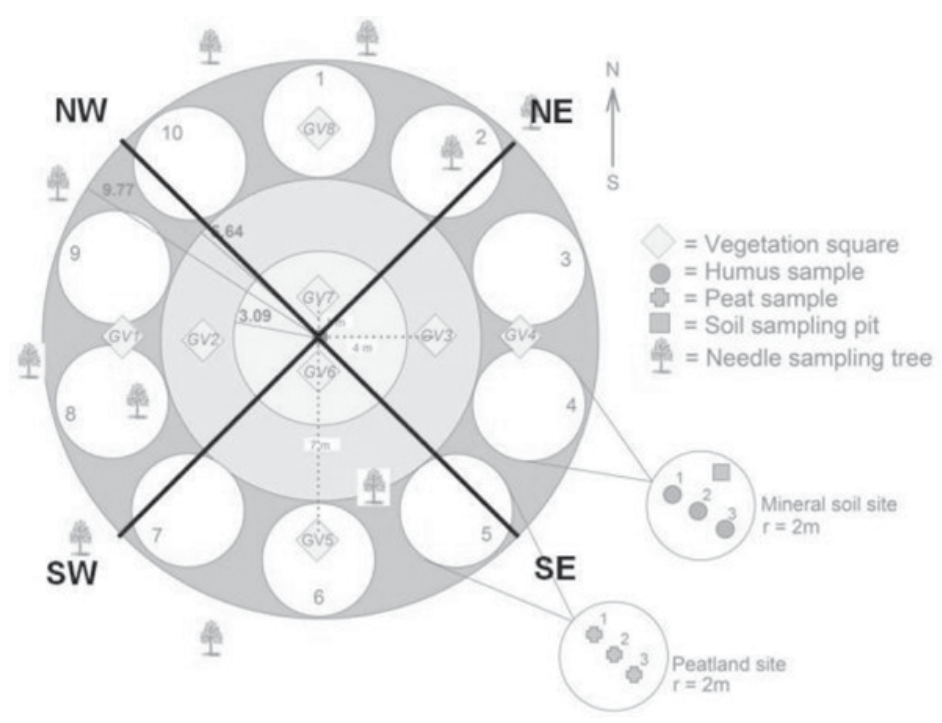

Figure 1. Sampling design on the $300-\mathrm{m}^{2}$ circular plot. Two inventory lines for plant survey were placed from south-west (SW) to north-east (NE) and from south-east (SE) to north-west (NW).

\section{RESULTS AND DISCUSSION}

\subsection{Measured plant dimensions and weights}

Measured dimensions and mass per individual of the studied plant species are presented in Table 2. Leaves and inflorescences of Deschampsia flexuosa were measured separately since the dry mass distribution of that grass is polarized. Dry mass of single plants varied from 0.01 to $5.90 \mathrm{~g}_{\mathrm{dw}}$ on mineral soil sites. Bilberry had the largest dry mass and grass and herb species the smallest ones. On the pine mire the dry mass of individual plant species varied from 0.17 (cloudberry) to 4.23 (heather) $\mathrm{g}_{\mathrm{dw}}$. Large variation in dimensions of mire plants was observed, including also dry mass of mire plants. This was an expected result because of diverse site types on Lastensuo mire. To compare, the default values in the ERICA Assessment Tool [8] for the shrub and the grass/herb ellipsoids is $2.62 \mathrm{~g}$, apparently fresh-weight which would indicate values of around $15 \mathrm{~g}_{\mathrm{dw}}$ for a shrub ellipsoid and around $5 \mathrm{~g}_{\mathrm{dw}}$ for a grass/herb ellipsoid. In our dataset, these would be the larger shrubs or 1-2 orders of magnitude heavier grasses or herbs.

Dry matter content in the samples varied from 0.08 to $0.56 \mathrm{gdw} / \mathrm{gfw}$ clearly relating to the woodiness of the plant species; of all samples, across the different site types, shrubs had the highest, $0.41 \pm 0.02$ $\mathrm{g}_{\mathrm{dw}} / \mathrm{g}_{\mathrm{fw}}( \pm$ standard error; $\mathrm{N}=51)$, lichen $0.49 \pm 0.08(4)$, moss $0.26 \pm 0.05(5)$, and grasses and herbs $0.18 \pm 0.04(16)$.

\subsection{Dose rates and the geometry issue}

Dose rates for the plants in our study, directly using the means of the measured largest extents of the geometry (i.e. the ellipsoid being drawn around the plant individual) and their measured mean mass (fw) as input values to the ERICA assessment tools, are about $4.6 \times 10^{-8} \mu \mathrm{Gy} / \mathrm{h}$ from I- 129 , $6.3 \times 10^{-12} \mu \mathrm{Gy} / \mathrm{h}$ for Ni-59 and $2.0 \times 10^{-12} \mu \mathrm{Gy} / \mathrm{h}$ for Se-79, proportionally to the source term. The order of magnitude of the dose rates is as expected in our case [9]. As seen many times earlier, e.g. [1], the variability between the plant species and site type is negligible; the size does not matter very much. Lichens and mosses were excluded from these dose rate calculations due to lack of measurement data on mass per individual, but see the discussion below. 


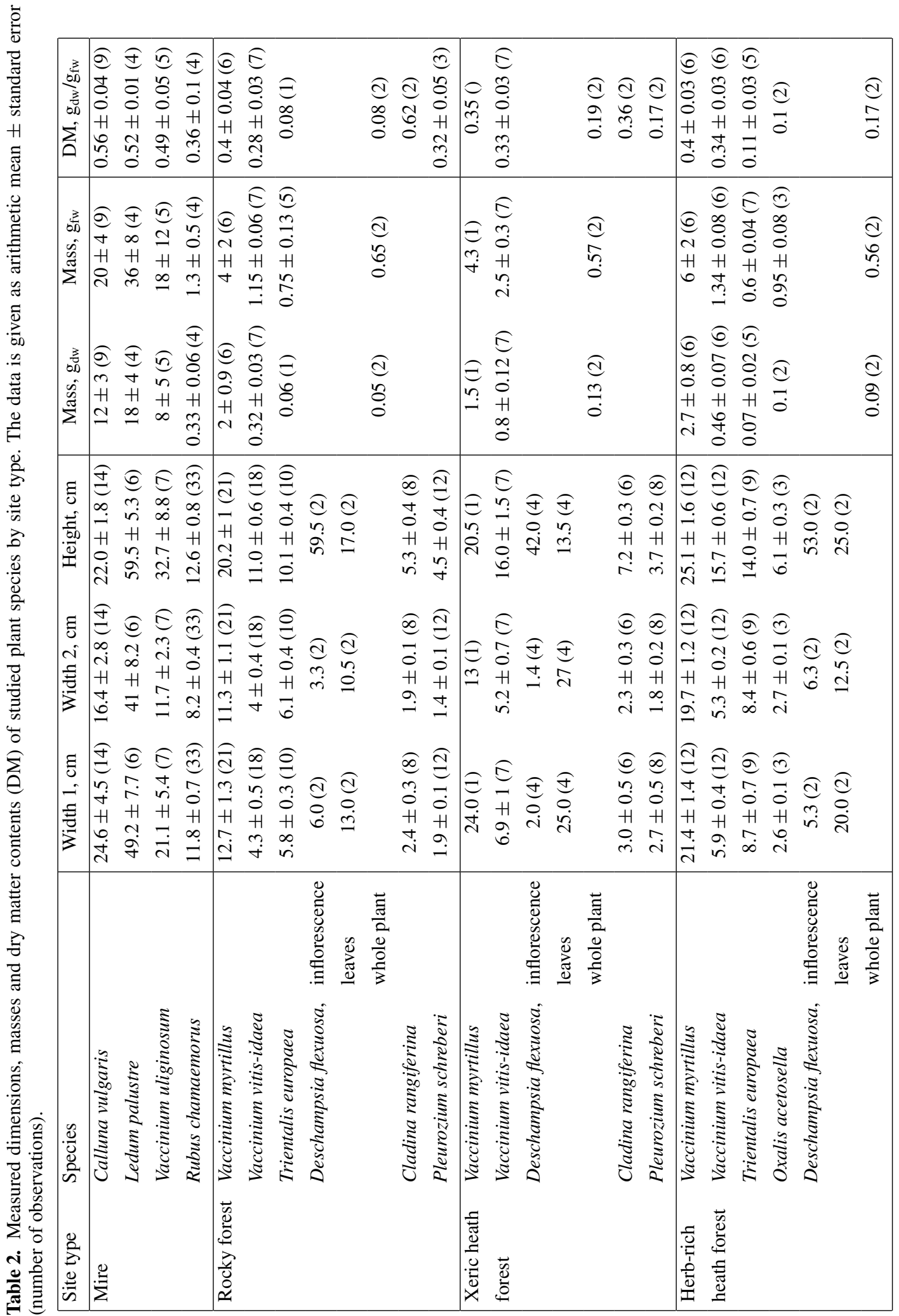




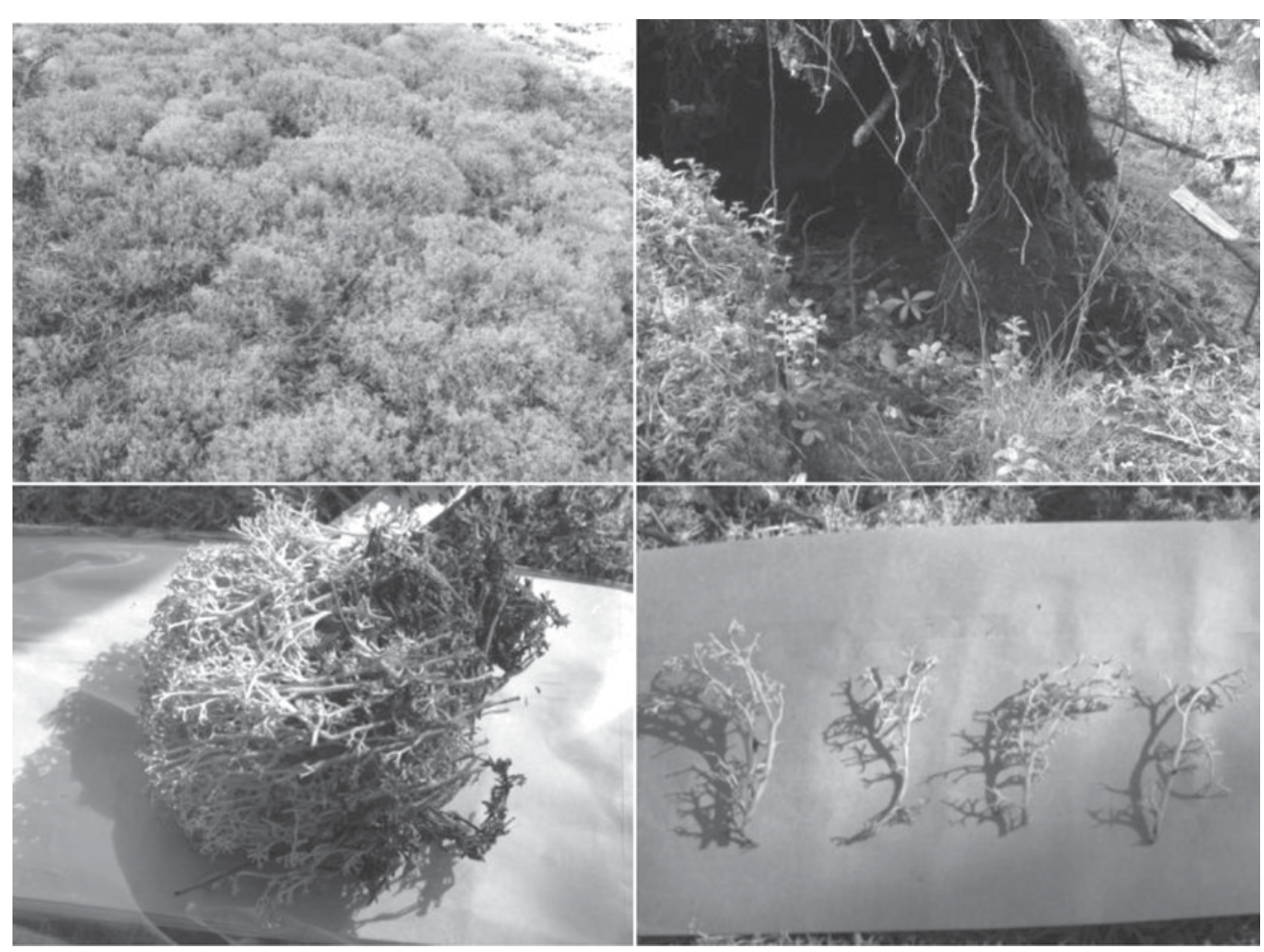

Figure 2. Examples of the variable geometries. Top row: part of a common wide lichen mat of Cladina rangiferina in contrast to individuals of Deschampsia flexuosa well separated from each other but still in proximity of other plants. Bottom: the mat of Cladina rangiferina further dissected into a block and single individuals. Photos: Lasse Aro.

However, ERICA computes the dose conversion factors to the plant ellipsoid assuming anyway a density of $1 \mathrm{~g} / \mathrm{cm}^{3}$ (assumedly fresh weight) and scaling with the user-defined dimensions. Apparently, the weight of the organism is then used only together with the concentration ratio to calculate only the radionuclide concentration within the organism to be multiplied with the dose conversion factors derived earlier to get the dose rate. Using the ERICA default mass and ellipsoid scaling parameters (X and $\Xi$ ), and the density of $1 \mathrm{~g} / \mathrm{cm}^{3}$, the ellipsoid would be $2.5 \times 0.5 \times 0.5 \mathrm{~cm}^{3}$ for both the shrubs and the grass/herb. This is very small compared to the real sizes of the plants for which the reference organisms should be representative - naturally, due to the assumption of all of the ellipsoid here to have the density of water. Thus, using the real weight of the plant exemplar is needed to derive the proper activity concentration, but for the dimensions the ellipsoids should be 'full of itself', i.e. no air as there largely is if the dimensions are taken from the virtual ellipsoid surrounding the individual as above. This would require a collection of tiny ellipsoids to represent the geometrical configuration of a specific plant type, possibly with a curved, thin cylinder for the stem; establishing a database of the dimensions would be very tedious, especially if correlated weights of the parts would be needed as the weighing of very light plant parts fresh and dry is indeed challenging. Luckily, we did photograph most of our sampled individuals so at least the proportional dimensions can be estimated (e.g. Fig. 2) if needed. Another, a technical solution would be to calculate the reduced dimensions of the $1-\mathrm{g} / \mathrm{cm}^{3}$ ellipsoid from the weight and the measured ratios of dimensions (even here the squarrose branches and leaves would require some thought, though), but this would be virtually scrunching all the plant of concern into a tight egg-shaped package with the less air the more woody structure it has (virtually, had). 
Furthermore, as the 'solid' plant parts are usually rather small, absorption of the radiation type within the ellipsoid or largely passing it through needs to be considered. Also co-irradiation between plant individuals or their parts close each other may be an issue; e.g. lichens and mosses form extensive mats of intertwined individuals (fig. 2). In our study, Cladina rangiferina had a dry matter content of 0.014-0.022 $\mathrm{g}_{\mathrm{dw}} / \mathrm{cm}^{3}$ (xeric heath and rocky forest, respectively) and Pleurozium schreberi 0.010-0.016 $\mathrm{g}_{\mathrm{dw}} / \mathrm{cm}^{3}$, respectively, or $0.04-0.06 \mathrm{~g}_{\mathrm{fw}} / \mathrm{cm}^{3}$. The ERICA default weight of a lichen/bryophyte $(0.11 \mathrm{~g})$ seems to be rather large as clearly in a block of $5 \times 5 \times 5 \mathrm{~cm}^{3}$, or $125 \mathrm{~cm}^{3}$, there obviously are more than the 45 individuals (fig. 2, compare the two lower photos with each other). Based on our experience, the individuals are very tightly packed to the mat formation; it was difficult to separate the individuals intact. Certainly, this kind of mat of vegetation could be considered as a large ellipsoid but it is not evident how large area should be delineated for this.

\section{CONCLUSIONS}

As a part of the site characterisation activities to feed in the safety case for the spent nuclear fuel repository to be constructed in Olkiluoto, Finland, dimensions and masses of key plant species were measured from different site types within boreal forest. As expected from earlier studies, the size does not matter, within reasonable groups of organisms, but with aiming at conceptual integrity in the assessment, defining appropriate dimensions for the ellipsoids representing plants is in most cases difficult as the shape and structure of the plants clearly deviate from the ellipsoidal geometry assumed in the prevailing assessment methodologies. However, a collection of small ellipsoids to represent different parts of plants is not readily supported by the modelling tools and also the interpretation of such results needed consideration. Furthermore, lichen and mosses usually form rather extensive mats with a large density of intertwined individuals - especially in cases like this, co-irradiation between the neighbouring 'ellipsoids' might be an issue for some radionuclides. The derived dose rates to the representative plants or their groups seem to be rather robust against the details of geometry but drawing a coherent and credible picture of the methodology would benefit from further effort.

\section{References}

[1] Smith K., Robinson C., Jackson D., de la Cruz I., Zinger I. and Avila, R., Posiva Working Report 2010-69 (2010) 1-92.

[2] Tamminen P., Aro L. and Salemaa M., Posiva Working Report 2007-78 (2007) 1-109.

[3] Reinikainen A., Mäkipää R., Vanha-Majamaa I. and Hotanen, J.-P. (eds.), Kasvit muuttuvassa metsäluonnossa [summary: Changes in the frequency and abundance of forest and mire plants in Finland since 1950] (Kustannusosakeyhtiö Tammi, Helsinki, 2000) pp. 1-384.

[4] Saramäki J. and Korhonen K.T., Posiva Working Report 2005-39 (2005) 1-79.

[5] IAEA, Modelling radiation exposure and radionuclide transfer for non-human species: Report of the Biota Working Group of EMRAS Theme 3, pre-release (International Atomic Energy Agency, Vienna, 2010) pp. 1-238.

[6] Haapanen R., Aro L., Helin J., Hjerpe T., Ikonen A.T.K., Kirkkala T., Koivunen S., Lahdenperä A.-M., Puhakka L., Rinne M. and Salo, T., POSIVA Report 2009-02 (2009) 1-416.

[7] Haapanen R., Aro L., Kirkkala T., Koivunen S., Lahdenperä A.-M. and Paloheimo A., Posiva Working Report 2010-67 (2010) 1-217.

[8] Brown J. E., Alfonso B., Avila R., Beresford N.A., Copplestone D., Pröhl G. and Ulanovsky A., J. Environ. Radioact. 99 (2008) 1371-1383.

[9] Hjerpe T., Ikonen A.T.K. and Broed, R., POSIVA Report 2010-03 (2010) 1-185. 